\title{
Commentary
}

\section{Tetrabenazine, Depression and Suicide: Good News}

\author{
Russell L. Margolis* \\ Laboratory of Genetic Neurobiology, Division of Neurobiology, Department of Psychiatry, Johns Hopkins University \\ School of Medicine, Baltimore, MD, USA
}

\begin{abstract}
Tetrabenzaine, $\left(\right.$ Xenzine $^{\mathrm{TM}}$, Lundbeck) a reversible inhibitor of vesicular monoamine transporter 2 , is thus far the only drug approved by the FDA specifically for Huntington's disease. The target symptom is chorea, with a mechanism of action related to its capacity to deplete monoamines [1]. Tetrabenazine has been available since the 1950's, and had been repeatedly shown in large case series to benefit hyperkinetic movements associated with a number of disorders, including chorea associated with HD and tardive dyskinesia, tics associated with Tourette's syndrome, dystonia, and myoclonus [2]. While some of the same effects can be achieved with antipsychotic agents (e.g., haloperidol, olanzapine) [3], the evidence supporting the use of these agents is mixed, and antipsychotics can place patients at risk tardive dyskinesia, which is not a side effect of tetrabenazine. Hence the FDA approval of tetrabenazine was a major milestone.
\end{abstract}

The use of tetrabenzine by clinicians has been held back, in part, by the highly publicized potential side effects of depression and suicide, including a "Black Box" warning [4]. Indeed, as Dorsey et al note, one participant of 54 receiving tetrabenazine in the critical Phase III tetrabenazine trial committed suicide [5]. The prominence of the monoamine hypothesis of depression into the $1990 \mathrm{~s}$ provided ample theoretical justification for this concern. Empiric studies of

\footnotetext{
*Correspondence to: Russell L. Margolis, M.D., Laboratory of Genetic Neurobiology, Division of Neurobiology, Department of Psychiatry, Johns Hopkins University School of Medicine, Baltimore, MD, USA. E-mail: rmargoli@jhmi.edu.
}

tetrabenazine, including the Phase III trial that proved central to its approval for HD, did not allay concerns, though evidence supporting increased depression and suicide has been mixed, and is often confounded by the risk of depression and suicide in the underlying condition for which tetrabenazine has been applied, including HD [6, 7].

Now Dorsey and colleagues provide evidence that tetrabenazine does not increase the rates of depression, suicidality, or suicide. Using data collected during the COHORT observational study of HD [8], they demonstrated no excess of depression, suicidality, or suicide attempts in the patients taking tetrabenazine compared to those who did not. The authors point out a variety of limitations, most prominently inclusion of only those patients willing to enroll in COHORT, the potential that participating in the study may itself have decreased the chance of depression and suicidaility, and the nonrandom selection of which patients received tetrabenazine. In addition, "depression" and "suicidality" were defined based on answers to single questions in the UHDRS rather than on the basis of a more comprehensive examination. On the other hand, the study was comparatively large, with greater than 350 participant-years of tetrabenazine exposure.

While not definitive, Dorsey et al provides some reassurance that the risk of depression and suicidality from tetrabenazine may not be as great as previously feared. This is good news for the treatment of HD, and also for the off-label use of tetrabenazine in other dyskinesias. It will be interesting to determine the effect on depression and suicidality of compounds related to 
tetrabenazine, currently undergoing clinic trials in HD (SD-809, Auspex Pharmaceuticals, Inc, FIRST-HD, http://www.clinicaltrials.gov/ct2/show/NCT01795859 ?term=first-hd\&rank=1) and in tardive dyskinesia (Neurocine, INC, NBI-98854, e.g., KINECT-2, http:// clinicaltrials.gov/ct2/show/NCT01733121?term=NBI98854\&rank=5).

\section{DISCLOSURES}

The author is a site investigator for a trial of NBI98854, Neurocrine, Inc and a site coinvestigator for SD-809, Auspex, Inc).

\section{REFERENCES}

[1] Guay DR. Tetrabenazine, a monoamine-depleting drug used in the treatment of hyperkinetic movement disorders. Am J Geriatr Pharmacother. 2010;8:331-73.

[2] Chen JJ, Ondo WG, Dashtipour K, Swope DM. Tetrabenazine for the treatment of hyperkinetic movement disorders: A review of the literature. Clin Ther. 2012;34(7):1487-504.
[3] Adam OR, Jankovic J. Symptomatic treatment of Huntington disease. Neurotherapeutics. 2008;5(2):181-97.

[4] http://www.xenazineusa.com/hcp/prescribingxenazine; see also REMS statement, most recent modification: August 2013 NDA 21-894, Xenazine ${ }^{\circledR}$, Valeant Pharmaceuticals North America LLC http://www.fda.gov/downloads/Drugs/DrugSafe ty/PostmarketDrugSafetyInformationforPatientsandProviders/ ucm129514.pdf

[5] Huntington Study Group. Tetrabenazine as antichorea therapy in Huntington disease: A randomized controlled trial. Neurology. 2006;66(3):366-372.

[6] Schoenfeld M, Myers RH, Cupples LA, Berkman B, Sax DS, Clark E. Increased rate of suicide among patients with Huntington's disease. J Neurol Neurosurg Psychiatr. 1984;47(12):1283-7.

[7] Paulsen JS, Nehl C, Hoth KF, Kanz JE, Benjamin M, Conybeare R, McDowell B, Turner B. Depression and stages of Huntington's disease. J Neuropsychiatry Clin Neurosci. 2005;17(4):496-502.

[8] Dorsey ER, Beck CA, Darwin K, Nichols P, Brocht AF, Biglan KM, Shoulson I; Huntington Study Group COHORT Investigators. Natural history of Huntington disease. JAMA Neurol. 2013;70(12):1520-30. 